\title{
Trans Fatty Acids in the Hong Kong Food Supply
}

\author{
Stephen W. C. Chung, ${ }^{1}$ S. K. Tong, ${ }^{1}$ Violette F. P. Lin, ${ }^{2}$ Melva Y. Y. Chen, ${ }^{2}$ \\ Janny K. M. Ma, ${ }^{2}$ Y. Xiao, ${ }^{2}$ and Y. Y. Ho ${ }^{3}$ \\ ${ }^{1}$ Food Research Laboratory, Food and Environmental Hygiene Department, Centre for Food Safety, \\ 4/F Public Health Laboratory Centre, 382 Nam Cheong Street, Hong Kong \\ ${ }^{2}$ Risk Assessment Section, Food and Environmental Hygiene Department, Centre for Food Safety, 43/F, \\ Queensway Government Offices, 66 Queensway, Hong Kong \\ ${ }^{3}$ Food and Environmental Hygiene Department, Centre for Food Safety, 45/F, Queensway Government Offices, \\ 66 Queensway, Hong Kong
}

Correspondence should be addressed to Stephen W. C. Chung; swcchung@fehd.gov.hk

Received 7 May 2013; Revised 18 July 2013; Accepted 20 July 2013

Academic Editor: Ioannis G. Roussis

Copyright (C) 2013 Stephen W. C. Chung et al. This is an open access article distributed under the Creative Commons Attribution License, which permits unrestricted use, distribution, and reproduction in any medium, provided the original work is properly cited.

\begin{abstract}
This study aimed to examine trans fatty acids (TFA) content of 142 individual food items, including bakery, fast food, and other fatty food that may contain high level of TFA. TFA was detected in all samples, except for four samples including one plain bread, one sponge cake, and two batter-made foods (egg roll and eggette) samples. For those found to contain detectable TFA, the content ranged up to $4.7 \mathrm{~g} / 100 \mathrm{~g}$ of food or $17.3 \%$ of total lipids. On a per 100 grams of food basis, the highest mean TFA content among the 18 food subgroups was the doughnuts/French toast subgroup $(0.95 \mathrm{~g})$, followed by the other pastries subgroup $(0.49 \mathrm{~g})$ and the bread with filling/topping subgroup $(0.44 \mathrm{~g})$. Among the samples, the highest TFA content is from a doughnut $(4.7 \mathrm{~g} / 100 \mathrm{~g})$, followed by two cream-filled bread with shredded coconut $(1.8$ and $1.4 \mathrm{~g} / 100 \mathrm{~g})$ and a sweetheart cake $(1.7 \mathrm{~g} / 100 \mathrm{~g})$. Only consuming one whole piece of doughnut would have reached $100 \%$ of the maximum daily TFA intake as recommended by WHO based on a $2000 \mathrm{kcal}$ diet. About $78 \%$ of samples had TFA $\leq 0.3 \mathrm{~g} / 100 \mathrm{~g}$ food. For the majority of the food samples available in Hong Kong, if TFA was present, C18:1 trans would possibly be the predominant one.
\end{abstract}

\section{Introduction}

The World Health Organization [1] predicted that coronary heart disease (CHD) will remain as the third killer of the world in the coming decades. In Hong Kong, the latest data from the Department of Health shows that CHD has been the 2nd killer since 2001 [2]. As there is a lack of TFA intake data in Hong Kong, the trans fatty acids (TFAs) content of the diet in Hong Kong could only be estimated in the range from less than 1g/person/day in Asian and Pacific countries to $10-20 \mathrm{~g} / \mathrm{person} /$ day in subpopulations of some Western countries [3]. Intake of excessive TFA would increase the risk of $\mathrm{CHD}$, and its effect is considered to be even greater than saturated fatty acids (SFAs). TFA can increase the risk of CHD by not only raising the level of low density lipoprotein (LDL) cholesterol, but also reducing the high density lipoprotein (HDL) cholesterol [4]. Thus, the World Health Organization
[5] has recommended a daily TFA intake of less than $1 \%$ of overall energy intake (i.e., about $2.2 \mathrm{~g} /$ day for a $2000 \mathrm{kcal}$ diet) for chronic diseases prevention.

Internationally, there have been increasing concerns on TFA content in foods. The intake and potential adverse health effects of TFA in developed and developing countries have received considerable attention $[4,6-9]$. Some countries have introduced legislations to regulate TFA level in certain foods or mandated TFA labelling on foods so as to lower TFA consumption in the populations [10-12]. In these countries, the TFA content in foods has been lowered as manufacturers and restaurants took initiatives to reformulate their products [13-15]. A recently published review [16] has reinforced that TFA policies were associated with significant reductions in TFA levels in the food supply. However, both individualand policy-level initiatives to decrease TFA consumption should continue particularly in subgroups and in developing 
countries with high consumption of partially hydrogenated vegetable oils (PHVO) [17]. Furthermore, Ansorena et al. [18] showed the TFA content in bakery products in Spain in 2012 has significantly lowered and highlighted the importance of updating food composition databases in order to accurately estimate the real and current intake of TFA. Similarly, Roe and Finglas of the United Kingdom [19] made the same comment on the importance of updating the food composition database on foods with TFA.

Hong Kong is a gourmet paradise; however, there is limited data on the level of TFA in locally available foods. In addition to some notorious high TFA Western foods (e.g., French fries, biscuits, cakes, and instant soup), many indigenous foods may contain significant amounts of TFA as they are deep fried (e.g., fritter and sesame seed ball) or are probably manufactured with PHVO (e.g., sweetheart cake, and egg tart) for its lower cost compared with other fats, its ability to prolong the shelf-life of products, and its desirable characteristics imparted to the food. There was no labelling requirement of nutrients including TFA in prepackaged foods prior to the labelling regulation enacted on May 28, 2008, including the grace period of 2 years [20].

The purpose of the present study was to obtain the TFA level in Hong Kong so as to gauge the risk of excessive TFA intake. Selected food products in this study were generally considered to be the major sources of TFA in the Western diets, and it also covered many indigenous foods that potentially contained high level of TFA. This paper is the first study in Hong Kong which revealed the TFA content in mainly bakery products including indigenous foods and common Western fast foods as well as other high fat foods.

\section{Materials and Methods}

2.1. Sampling of Foods. A total of 142 items were identified and sampled for TFA analysis. They were foods commonly consumed in Hong Kong that might contain a significant TFA content as reported in a corresponding item in the literature. Food samples were purchased and prepared for analysis between March and December 2007. They were collected from retail outlets including catering suppliers and takeaway outlets, food premises, and supermarkets in different districts in Hong Kong. Sample selection was also based on the popularity of the brands for that category. All samples were ready-to-eat and required no cooking. Food samples were collected individually for analysis. However, each sample was made up of 1 to 10 units to provide at least $200 \mathrm{~g}$ for chemical analysis. Amongst the samples, quite a significant portion of prepackaged products were imported from overseas countries, especially in the subgroups of biscuits, potato products, instant soup, chocolate, chips, and spread. Table 1 shows the samples selected which were categorised into bakery products or fast foods/others and were separated into 18 food subgroups.

The samples were analysed by the Food Research Laboratory (FRL) of Centre for Food Safety (CFS) to determine the content of TFA, SFA, and total lipids. FRL is accredited under ISO/IEC 17025:2005 by the Hong Kong Accreditation Service for analysing the concerned parameters. Except for
TABLE 1: Food items selected for analysis in this study.

\begin{tabular}{|c|c|}
\hline Food subgroup & Food item \\
\hline \multicolumn{2}{|l|}{ Bakery products } \\
\hline Batter-made foods (11) & $\begin{array}{l}\text { Egg rolls (5), eggette ( } 3 \text { ), and } \\
\text { waffles ( } 3 \text { ) }\end{array}$ \\
\hline Biscuits (10) & $\begin{array}{l}\text { Biscuits (4), crackers (3), and } \\
\text { cookies (3) }\end{array}$ \\
\hline Creamy biscuits (5) & $\begin{array}{l}\text { Cream crackers ( } 2) \text {, and } \\
\text { wafers ( } 3 \text { ) }\end{array}$ \\
\hline Pastries (10) & $\begin{array}{l}\text { Pastries (5), croissant (2), and } \\
\text { sweetheart cake ( } 3 \text { ) }\end{array}$ \\
\hline Plain bread (11) & $\begin{array}{l}\text { White bread (3), wholemeal } \\
\text { bread (4), and sweet bun ( } 4)\end{array}$ \\
\hline Bread with filling/topping (12) & $\begin{array}{l}\text { Cream-filled bun ( } 3) \text {, } \\
\text { pineapple bun with/without } \\
\text { butter (6), and sausage bun ( } 3)\end{array}$ \\
\hline Doughnuts/French toast (7) & $\begin{array}{l}\text { Doughnuts (4), and french } \\
\text { toast (3) }\end{array}$ \\
\hline Sponge cakes (13) & Sponge cakes (13) \\
\hline Creamy cakes (4) & Creamy cakes (4) \\
\hline Chinese fried dough (6) & $\begin{array}{l}\text { Fried fritter ( } 3 \text { ), and fried } \\
\text { sesame seed ball ( } 3 \text { ) }\end{array}$ \\
\hline Egg tarts (7) & $\begin{array}{l}\text { Shortcrust pastry (3), puff } \\
\text { pastry (3), and portuguese (1) }\end{array}$ \\
\hline
\end{tabular}

Fast foods/others

\begin{tabular}{ll} 
Potato products (11) & $\begin{array}{l}\text { French fries (3), potato wedges } \\
(1), \text { and potato chips (7) }\end{array}$ \\
Instant noodles (7) & $\begin{array}{l}\text { Instant noodles without } \\
\text { seasonings (7) }\end{array}$ \\
Chocolate (6) & $\begin{array}{l}\text { Chocolate (6) } \\
\text { Ready-to-drink (3), and soup } \\
\text { mix (3) }\end{array}$ \\
Instant soup (6) & Other chips (6) \\
Chips (6) & Chicken (3), and pork chop (1) \\
Deep-fried meat (4) & Peanut (4), and chocolate (2) \\
\hline Spread (6) &
\end{tabular}

The number in the bracket refers to the number of individual food samples.

deep-fried meat that bones were removed before analysis, the whole sample was homogenised and stored at $-20^{\circ} \mathrm{C}$ until they were analysed.

2.2. Analytical Determination of Fatty Acids. Analysis of fatty acids was performed according to the AOAC official method [21] 996.06 except that the duration of methylation increased from 45 to $60 \mathrm{~min}$, and the gas chromatographic conditions were as described here: (i) the column used was SP-2560 column $(100 \mathrm{~m} \times 0.25 \mathrm{~mm} \times 0.2 \mu \mathrm{m})$; (ii) the carrier gas was helium $(0.7 \mathrm{~mL} / \mathrm{min})$; (iii) the injector temperature was $225^{\circ} \mathrm{C}$ and injection volume at $1 \mu \mathrm{L}$; (iv) the split ratio was $150: 1$; (v) the temperature programme was $100^{\circ} \mathrm{C}$ for $4 \mathrm{~min}$, then increased at a rate of $3^{\circ} \mathrm{C} / \mathrm{min}$ to $240^{\circ} \mathrm{C}$ and held for $20 \mathrm{~min}$; and (vi) the temperature of FID detector was at $285^{\circ} \mathrm{C}$.

In brief, weigh a test portion of the homogenised sample that contained around 50-100 mg total lipids into a Mojonnier flask, and the lipids of the samples were then hydrolysed 
by $8.3 \mathrm{M}$ hydrochloric acid. Pyrogallic acid was added to prevent oxidative degradation of fatty acids during acid hydrolysis, and $10 \mathrm{mg}$ triundecanoin was added as internal standard. After hydrolysis, fatty acids were extracted into diethyl ether which were concentrated. Boron trifluirode (7\%, $2 \mathrm{~mL}$ ) was then added as derivatising agent, and fatty acids were methylated to fatty acid methyl esters (FAMEs) by heating at $100^{\circ} \mathrm{C}$ for an hour. FAMEs yielded were quantitatively measured by using a gas chromatograph equipped with flame ionisation detection system.

2.3. Analytical Determination of Total Lipids. Analysis of total fat in samples was performed according to the AOAC official method [21] 922.06. In brief, $2 \mathrm{~g}$ sample was moistened with ethanol, and the lipids in the sample were hydrolysed by $8.3 \mathrm{M}$ hydrochloric acid. After that, the lipids were extracted into diethyl ether which was then evaporated to dryness. Total of lipids yielded was determined by weighing the residue.

2.4. Quality Control. For each batch of analysis of fatty acids (15 samples) or total lipids (10 samples), one blank, one spike, and one control sample were analysed for quality assurance purpose. For fatty acids, a control food sample (beef-pork fat blend) was run throughout the whole study. The maximum precision of duplicate analysis and average recovery spiked triglycerides were 9.5 and $96 \%$. The CVs for main fatty acids were $6.9 \%$ for $\mathrm{C} 14: 0,3.6 \%$ for $\mathrm{C} 16: 0,3.5 \%$ for $\mathrm{C} 18: 0,9.7 \%$ for $\mathrm{C} 16: 1 \mathrm{n}-7 \mathrm{t}$, and $11.8 \%$ for C18:2n-6ct, respectively. For total lipids, the average spiked recovery, maximum precision of duplicate analysis, and CV of a control sample were 101, 5.5, and $1.87 \%$, respectively.

2.5. Data Interpretation. The contents of TFA, SFA, and total lipids are presented in per $100 \mathrm{~g}$ food. The TFA content is further presented in per $100 \mathrm{~g}$ total lipids.

Total lipids referred to the sum of triglycerides, phospholipids, wax ester, sterols, and minor amount of nonfatty material. SFA referred to the sum of 13 isomers (C4:0, C6:0, C8:0, C10:0, C12:0, C14:0, C15:0, C16:0, C17:0, C18:0, C20:0, C22:0, and C24:0), and TFA referred to the sum of 8 isomers (C14:1n-5t, C16:1n-7t, C18:1 trans (sum of all position isomers), C18:2n-6tt, C18:2n-6ct, C18:2n-6tc, C20:1n-9t, and C22:1n-9t).

The mean (and range) of the individual samples of each group was presented as the content of each food item in the report. The values of fatty acids and total lipids were rounded to 2 significant figures rather than 2 decimal figures and in agreement with the decimal place of the limit of detection (LOD). The values of fatty acids and total lipids were reported as "ND" if the level was below LOD.

When the value of fatty acids or total lipids of a food was between LOD and the limit of quantitation (LOQ), the average of LOD and LOQ would be used for calculating the mean and the range. The LOD and LOQ of each individual TFA are 0.005 and $0.01 \mathrm{~g} / 100 \mathrm{~g}$, respectively. The LOD and LOQ of each individual SFA are in the range of 0.0005-0.005 and $0.002-0.02 \mathrm{~g} / 100 \mathrm{~g}$, respectively. The LOD and LOQ for total lipids are 0.1 and $0.3 \mathrm{~g} / 100 \mathrm{~g}$, respectively.

\section{Results and Discussion}

3.1. TFA, SFA, and Total Lipids Content across Food Groups. The average levels of TFA, SFA, and total lipids in the 18 food subgroups are shown in Table 2. Generally, the average TFA content of the bakery products group (except for the sponge cakes, the Chinese fried dough, and batter-made foods subgroups) was higher than that of the fast foods/other group (except for the chocolate subgroup). The highest mean TFA content was found in the doughnuts/French toast subgroup $(0.95 \mathrm{~g} / 100 \mathrm{~g}$ food), followed by the pastries subgroup $(0.49 \mathrm{~g} / 100 \mathrm{~g}$ food $)$, the bread with filling/topping subgroup $(0.44 \mathrm{~g} / 100 \mathrm{~g}$ food $)$, and the egg tart subgroup $(0.38 \mathrm{~g} / 100 \mathrm{~g}$ food). The bakery products group had a similar range of average SFA levels as the fast foods/others group (2.4-14 $\mathrm{g}$ and $2.2-13 \mathrm{~g} / 100 \mathrm{~g}$ food, resp.) but with a lower level of average total lipids content (except for the creamy biscuits subgroup) than the fast foods/others group (except for the instant soup subgroups).

In per $100 \mathrm{~g}$ of the $142 \mathrm{foods}$, TFA is present in almost all foods except for four food samples: a plain bread, a sponge cake, and two batter-made samples (one egg roll and one eggette). For the rest, TFA varied from $0.010 \mathrm{~g}$ in a plain sponge cake to $4.7 \mathrm{~g}$ in a doughnut. About $79 \%(112 / 142)$ samples had TFA equal to or less than $0.3 \mathrm{~g}$, a value which could be round to $0 \mathrm{~g}$ under the Hong Kong nutrition labelling scheme for prepackaged foods [22]. The SFA varied from $0.062 \mathrm{~g}$ in an instant soup to $22 \mathrm{~g}$ in a chocolate, and the total lipids varied from $0.9 \mathrm{~g}$ in an instant soup to $51 \mathrm{~g}$ in a peanut butter.

Due to resource constraints, the study had only covered limited number of food types and samples with high TFA content; more studies are warranted to examine other foods that may contain TFA such as oils and fats, common local dishes, and candies.

3.2. Food Items with TFA Content Greater Than $0.3 \mathrm{~g}$ per $100 \mathrm{~g}$ of Food. A total of 31 food items had TFA content more than $0.3 \mathrm{~g} / 100 \mathrm{~g}$ which were distributed in these subgroups (number of items): pastries (5), bread with filling/topping (5), biscuits (3), plain bread (4), egg tarts (4), batter-made foods (3), doughnuts/French toast (2), creamy biscuits (1), creamy cakes (1), chocolate (1), potato products (1), and spread (1). Table 3 shows their TFA content in each $100 \mathrm{~g}$ of foods (in descending order of the respective subgroups) and in each common unit of foods.

In the batter-made foods subgroup, all egg roll samples examined in this study contained a significant amount of TFA ( 0.34 to $1.0 \mathrm{~g} / 100 \mathrm{~g}$ food). Egg roll is a popular snack in Hong Kong which is a layer of egg batter baked on a hot flat metal plate. The product may be rolled up into a cylindrical shape or a square shape, and it may be sold plainly or stuffed with pork floss, seaweed, or sesame/coconut/candy mixture, and so forth. It is possible that TFA is produced during the high heat cooking of the ingredients involving oils and fats or the addition of PHVO in the ingredients.

Within the biscuits, creamy biscuits, and pastries subgroups, TFA found in wafers, cookies, and sweet puff pastry is in line with other studies. For instance, a wide range of TFA content has been reported in sweet pastry in Australia 
TABLE 2: The content of trans fatty acids, saturated fatty acids, and total lipids in food (mean (range)).

\begin{tabular}{|c|c|c|c|c|}
\hline \multirow{2}{*}{ Food group } & \multirow{2}{*}{$n$} & \multicolumn{3}{|c|}{$\mathrm{g} / 100 \mathrm{~g}$ food } \\
\hline & & Trans fatty acids & Saturated fatty acids & Total lipids \\
\hline \multicolumn{5}{|l|}{ Bakery products } \\
\hline Batter-made foods & 11 & 0.19 (ND-1.0) & $6.2(0.84-17)$ & $17(2.8-35)$ \\
\hline Biscuits/cookies & 10 & $0.28(0.041-0.83)$ & $9.1(3.9-15)$ & $20(9.0-27)$ \\
\hline Creamy biscuits & 5 & $0.33(0.052-1.3)$ & $14(9.2-18)$ & $29(24-31)$ \\
\hline Pastries & 10 & $0.49(0.041-1.7)$ & $10(4.5-17)$ & $24(17-31)$ \\
\hline Plain bread & 11 & $0.21(\mathrm{ND}-0.57)$ & $2.7(1.3-5.2)$ & $6.4(2.9-10)$ \\
\hline Bread with filling/topping & 12 & $0.44(0.076-1.8)$ & $6.7(3.5-11)$ & $16(10-26)$ \\
\hline Doughnuts/French toast & 7 & $0.95(0.066-4.7)$ & $4.2(3.3-8.9)$ & $22(11-30)$ \\
\hline Sponge cakes & 13 & $0.090(\mathrm{ND}-0.22)$ & $4.0(1.4-8.2)$ & $12(5.0-19)$ \\
\hline Creamy cakes & 4 & $0.36(0.014-0.90)$ & $7.7(5.4-11)$ & $19(13-25)$ \\
\hline Chinese fried dough & 6 & $0.092(0.034-0.15)$ & $2.4(1.1-4.1)$ & $19(10-30)$ \\
\hline Egg tarts & 7 & $0.38(0.12-0.82)$ & $7.6(5.3-13)$ & $19(15-26)$ \\
\hline \multicolumn{5}{|l|}{ Fast foods/others } \\
\hline Potato products & 11 & $0.13(0.035-0.38)$ & $6.8(1.4-13)$ & $26(12-39)$ \\
\hline Instant noodles & 7 & $0.095(0.030-0.24)$ & $8.6(7.5-10)$ & $20(18-22)$ \\
\hline Chocolate & 6 & $0.20(0.045-0.76)$ & $13(6.2-22)$ & $32(23-40)$ \\
\hline Instant soup & 6 & $0.030(0.016-0.067)$ & $2.2(0.062-7.6)$ & $4.9(0.9-14)$ \\
\hline Chips & 6 & $0.081(0.037-0.13)$ & $5.2(2.0-8.3)$ & $23(18-28)$ \\
\hline Deep-fried meat & 4 & $0.089(0.059-0.14)$ & $5.8(4.1-8.5)$ & $20(13-25)$ \\
\hline Spread & 6 & $0.11(0.011-0.40)$ & $9.1(8.0-11)$ & $46(37-51)$ \\
\hline
\end{tabular}

$n$ is the number of individual food samples analysed.

$(0.6-1.3 \mathrm{~g} / 100 \mathrm{~g}$ food) [23] and in cookies and wafers in US (0-8.1 g/100 g food) [24].

Within the bread with filling/topping subgroup, high TFA content in cream-filled bread with shredded coconut and buttered pineapple bun stuffed may be due to the use of PHVO or the dairy ingredients in the bread. Besides that, TFA is expected to be found in croissants and doughnuts as reported in other studies. For example, the TFA level in croissants was reported to be $0.3-0.4 \mathrm{~g} / 100 \mathrm{~g}$ food in Australia [23], 3.0-14.6\% of fatty acids in Europe [25], and 0.7-45.3\% of fatty acids in Canada [26]. The TFA level in doughnuts was reported to be $0.2-6.6 \mathrm{~g} / 100 \mathrm{~g}$ food in Australia [23], $4.6 \%$ of fatty acids in Spain [27], and $1.1-31.8 \%$ of fatty acids in Europe [25]. The TFA levels in fine bakery products including doughnuts and croissants were reported to be $0.05-$ $3.50 \mathrm{~g} / 100 \mathrm{~g}$ food in Switzerland [28].

In the plain bread subgroup, it was not surprising to find TFA as similar results were reported in Europe (0.1\% to $17.4 \%$ fatty acids) [25]. There is limited comparison of TFA content between plain bread and wholemeal bread in literature; however, samples collected in this study seemed to show that in terms of TFA in each $100 \mathrm{~g}$ of food, wholemeal bread had slightly higher TFA than plain bread, nevertheless; the TFA content per unit of food is comparable in both types of bread (about $0.17 \mathrm{~g}$ per unit). It is likely that the texture of wholemeal bread is comparatively rough, butter or oil was added to improve the texture, and higher TFA content was found.

Egg tarts have two main types of crusts: shortcrust pastry or puff pastry; they are both filled with a rich custard and have different appearance. Among the 7 egg tart samples in the egg tarts subgroup, all the puff pastry ones had TFA content below $0.3 \mathrm{~g} / 100 \mathrm{~g}$ food, contrarily the Portuguese egg tart sample, and the shortcrust pastry ones had TFA content above $0.3 \mathrm{~g} / 100 \mathrm{~g}$ food. Since most egg tarts are not sold as prepackaged foods, consumers have to rely on their appearance to choose one with lower TFA level, that is, those made of shortcrust pastry. However, in order to generalise the results to all types of egg tarts, more studies shall be conducted to evaluate the TFA content in them.

When presenting the TFA content as per unit of food, it was found that some foods contained very high TFA and by consuming just a piece of the product, it would have contributed a significant amount of TFA in the diet. Among them, the highest one is from a piece of doughnut (brand A) $(2.20 \mathrm{~g})$, followed by a piece of croissant (brand B) $(1.62 \mathrm{~g})$, a piece of cream-filled bread with shredded coconut (brands $\mathrm{A}$ and $\mathrm{B})$ (1.52 $\mathrm{g}$ and $1.32 \mathrm{~g}$ ), and a piece of sweetheart cake (brand A) (1.27 g). Only consuming one whole piece of each would have reached $58 \%$ to $100 \%$ of the maximum daily TFA intake as recommended by WHO for a $2000 \mathrm{kcal}$ diet.

3.3. TFA Isomers in Food Groups. The average TFA content of the 11 subgroups of the bakery products group ranged from $0.48 \%$ to $4.3 \%$ total lipids in the Chinese fried dough subgroup and in the doughnuts/French toast subgroup, respectively (Table 4). Previous studies have also reported low TFA $(<0.50 \%$ total fat) in Chinese fried dough such as fritter [29] and high TFA (1.6\%-19.7\% of total lipids) in various bread such as croissants, doughnuts, and sausage rolls [23]. Besides Chinese fried dough, C18:1 trans was 
TABLE 3: Food items with TFA greater than $0.3 \mathrm{~g}$ per $100 \mathrm{~g}$ of food.

\begin{tabular}{|c|c|c|c|c|}
\hline \multirow[b]{2}{*}{ Food group } & \multirow[b]{2}{*}{ Product } & \multicolumn{3}{|r|}{ TFA } \\
\hline & & $\mathrm{g} / 100 \mathrm{~g}$ food & g/unit* & $\begin{array}{l}\text { Percentage of the daily } \\
\text { recommended intake of TFA by } \\
\text { one piece of food item }{ }^{\#}\end{array}$ \\
\hline \multirow{3}{*}{ Batter-made foods } & Egg roll (brand A) & 1.0 & 0.16 & 7.3 \\
\hline & Egg roll (brand B) & 0.48 & 0.09 & 4.1 \\
\hline & Egg roll (brand C) & 0.34 & 0.13 & 5.9 \\
\hline \multirow{2}{*}{ Biscuits } & Cookies (brand A) & 0.83 & 0.07 & 3.2 \\
\hline & Cookies (brand B) & 0.58 & 0.06 & 2.7 \\
\hline Creamy biscuits & Wafer (brand A) & 1.3 & 0.11 & 5.0 \\
\hline \multirow{6}{*}{ Pastries } & Sweetheart cake (brand A) & 1.7 & 1.27 & 58 \\
\hline & Croissant (brand A) & 0.98 & 0.36 & 16 \\
\hline & Croissant (brand B) & 0.81 & 1.62 & 74 \\
\hline & Sweet puff pastry (brand A) & 0.69 & 0.06 & 2.7 \\
\hline & Sweet puff pastry (brand B) & 0.43 & 0.04 & 1.8 \\
\hline & Croissant (brand C) & 0.36 & 0.17 & 7.7 \\
\hline \multirow{2}{*}{ Doughnuts/French toast } & Doughnut (brand A) & 4.7 & 2.20 & 100 \\
\hline & Doughnut (brand B) & 0.47 & 0.28 & 13 \\
\hline Creamy cakes & Swiss roll (brand A) & 0.90 & 0.90 & 41 \\
\hline \multirow{4}{*}{ Plain bread } & Wholemeal bread (brand A) & 0.57 & 0.17 & 7.7 \\
\hline & Wholemeal bread (brand B) & 0.51 & 0.18 & 8.2 \\
\hline & White bread (brand A) & 0.40 & 0.17 & 7.7 \\
\hline & Sweet bun (brand A) & 0.31 & 0.10 & 4.5 \\
\hline \multirow{5}{*}{ Bread with filling/topping } & Cream-filled bread w/shredded coconut (brand A) & 1.8 & 1.52 & 69 \\
\hline & Cream-filled bread w/shredded coconut (brand B) & 1.4 & 1.32 & 60 \\
\hline & Buttered pineapple bun (brand A) & 0.45 & 0.21 & 9.5 \\
\hline & Buttered pineapple bun (brand B) & 0.39 & 0.42 & 19 \\
\hline & Cream-filled bread w/shredded coconut (brand C) & 0.35 & 0.38 & 17 \\
\hline \multirow{4}{*}{ Egg tarts } & Portuguese egg tart & 0.82 & 0.43 & 20 \\
\hline & Egg tart (brand A) & 0.54 & 0.39 & 18 \\
\hline & Egg tart (brand B) & 0.43 & 0.41 & 19 \\
\hline & Egg tart (brand C) & 0.38 & 0.23 & 11 \\
\hline Chocolate & Chocolate (brand A) & 0.76 & 0.33 & 15 \\
\hline Potato products & French fries (brand B) & 0.38 & 0.53 & 24 \\
\hline Spread & Peanut butter (brand A) & 0.40 & 0.06 & 2.7 \\
\hline
\end{tabular}

the predominant TFA in most samples which echoes the findings in many bakery products by other studies [23, 25, 27, 28]. For Chinese fried dough, they mainly contain the cooking oil used for deep drying, and the TFA profile should be similar to that of cooking oil. Thus, C18:2 trans was the predominant TFA which echoes the findings of TFA profile in edible oil [30].

The average TFA content of the 7 subgroups of fast foods/others group ranged from $0.24 \%$ to $0.63 \%$ of total lipids in the spread group and in the instant soup group, respectively (Table 4). Compared with other studies, the TFA content in peanut butter and chocolate spread determined in this study was much lower than that reported in Australia (e.g., $0.8-1.4 \%$ of total lipids) [23]. Other foods such as chips, French fries, and chocolate also had lower TFA than other studies [23, 27-29, 31]. Similar to the results in the bakery products, C18:1 trans was the predominant TFA in most samples.

Regarding the abundance of TFA, most of the tested samples had the descending sequence of C18:1 trans, C18:2n$6 \mathrm{ct}$, and C18:2n-6tc while other isomers were minimal. For the ratio of $\mathrm{C} 18: 2 \mathrm{n}-6 \mathrm{ct}$ to $\mathrm{C} 18: 2 \mathrm{n}-6 \mathrm{tc}$, it was normally closed to one. Such ratio was also found in the plain bread and doughnuts/French toast subgroups which were less than 0.7; this could be a result of using butter as one of the major ingredients in these food items. In contrast, the ratio 
TABLE 4: The content of TFA and selected isomers in food (mean (range) g/100 g total lipids).

\begin{tabular}{|c|c|c|c|c|c|}
\hline \multirow{2}{*}{ Food group } & \multirow{2}{*}{$n$} & \multicolumn{4}{|c|}{$\mathrm{g} / 100 \mathrm{~g}$ total lipids } \\
\hline & & Total TFA & C18:1 trans ${ }^{*}$ & C18:2n-6ct & C18:2n-6tc \\
\hline \multicolumn{6}{|l|}{ Bakery products } \\
\hline Batter-made foods & 11 & $1.1(\mathrm{ND}-5.9)$ & 0.88 (ND-4.9) & $0.094(\mathrm{ND}-0.25)$ & $0.094(\mathrm{ND}-0.28)$ \\
\hline Biscuits & 10 & $1.4(0.21-4.2)$ & $1.1(0.040-4.0)$ & $0.16(0.065-0.30)$ & $0.13(\mathrm{ND}-0.28)$ \\
\hline Creamy biscuits & 5 & $1.1(0.18-4.5)$ & $0.93(0.052-3.8)$ & $0.11(0.062-0.22)$ & $0.10(0.055-0.21)$ \\
\hline Pastries & 10 & $2.0(0.17-7.1)$ & $1.7(0.10-6.3)$ & $0.16(0.033-0.38)$ & $0.15(0.033-0.38)$ \\
\hline Plain bread & 11 & $3.3(\mathrm{ND}-8.9)$ & $3.1(\mathrm{ND}-8.3)$ & 0.17 (ND-0.34) & $0.41(\mathrm{ND}-1.2)$ \\
\hline Bread with filling/topping & 12 & $2.8(0.48-11)$ & $2.4(0.48-11)$ & $0.16(0.050-0.42)$ & 0.17 (ND-0.43) \\
\hline Doughnuts/French toast & 7 & $4.3(0.30-21)$ & $1.5(0.26-3.2)$ & $0.24(0.10-0.77)$ & $0.37(0.091-0.96)$ \\
\hline Sponge cakes & 13 & 0.75 (ND-1.8) & $0.44(0.067-1.5)$ & $0.16(\mathrm{ND}-0.42)$ & 0.15 (ND-0.40) \\
\hline Creamy cakes & 4 & $1.9(0.074-4.7)$ & $1.7(0.52-4.3)$ & $0.13(0.042-0.23)$ & $0.12(0.042-0.21)$ \\
\hline Chinese fried dough & 6 & $0.48(0.18-0.79)$ & $0.17(0.042-0.27)$ & $0.20(0.10-0.33)$ & $0.17(0.079-0.32)$ \\
\hline Egg tarts & 7 & $2.0(0.63-4.3)$ & $1.7(0.30-3.7)$ & $0.14(0.095-0.23)$ & $0.15(0.084-0.36)$ \\
\hline \multicolumn{6}{|l|}{ Fast foods/others } \\
\hline Potato products & 11 & $0.50(0.14-1.5)$ & $0.25(0.031-0.14)$ & $0.15(0.031-0.29)$ & 0.14 (ND-0.29) \\
\hline Instant noodles & 7 & $0.48(0.15-1.2)$ & $0.20(0.040-0.90)$ & $0.15(0.060-0.17)$ & $0.14(0.040-0.17)$ \\
\hline Chocolate & 6 & $0.63(0.14-2.4)$ & $0.50(0.056-2.4)$ & $0.053(0.025-0.097)$ & 0.041 (ND-0.091) \\
\hline Instant soup & 6 & $0.61(0.33-1.4)$ & 0.29 (ND-0.45) & 0.16 (ND-0.47) & 0.16 (ND-0.94) \\
\hline Chips & 6 & $0.35(0.16-0.57)$ & $0.10(0.035-0.28)$ & $0.13(0.065-0.72)$ & $0.12(0.061-0.26)$ \\
\hline Deep-fried meat & 4 & $0.45(0.30-0.70)$ & $0.26(0.11-0.50)$ & $0.11(0.055-0.20)$ & $0.090(0.040-0.17)$ \\
\hline Spread & 6 & $0.24(0.024-0.87)$ & $0.12(0.022-0.52)$ & $0.083(0.022-0.33)$ & 0.017 (ND-0.035) \\
\hline
\end{tabular}

$n$ is the number of individual food samples analysed; ${ }^{*}$ denotes the sum of all position isomers of C18:1t; ND refers to a level less than the detection limit of $0.005 \mathrm{~g} / 100 \mathrm{~g}$.

increased to greater than 4 for the spread subgroup in which the source of lipids comes mainly from peanut. Further studies in this area may provide a more conclusive finding for this hypothesis.

Distinction of TFAs according to their origin seems impossible as the isomers of C18:1 trans were not determined in this study, even though the conjugated linoleic acid (CLA) content C18:2T(9-cis, 11-trans) was analysed which may indicate the presence of ruminant origin of TFA in the food products [28]. All the 18 food subgroups have some levels of C18:2T(9-cis, 11-trans) except for the four subgroups: Chinese fried dough, instant soup, instant noodles, and potato products (data are not shown). It is likely that ruminant origin of the TFA is absent in these products of the four subgroups.

The wide range of TFA found within the same food groups was encouraging as it demonstrated that it was possible for the trade to lower the TFA content in the manufacturing process of making various foods. For example, blended or interesterified fats can be used in making puff pastry instead of PHVO. Interesterification is a process to replace hydrogenation of oil through interchanging fatty acids between molecules of triglyceride [7].

\section{Conclusions}

TFAs occur in a wide range of food products, especially in bakery products. About $78 \%$ of samples had TFA $\leq 0.3 \mathrm{~g} / 100 \mathrm{~g}$ food. Some of those indigenous foods such as egg tarts, sweetheart cakes, egg rolls, and popular bread such as cream-filled bread with shredded coconut are laden with hidden TFA which shall be consumed in moderation. For majority of the food samples available in Hong Kong, if TFA was present, C18:1 trans was the predominant one. Only for deep-fried food items, such as Chinese fried dough and chips, C18:2n-6ct and C18:2n-6tc have become the predominant TFAs. A more comprehensive study covering a wider range of products and more samples of each category is required before a conclusion can be drawn on the status of TFA content in Hong Kong foods.

\section{References}

[1] World Health Organization, The Atlas of Heart Disease and Stroke, 2004, http://www.who.int/cardiovascular_diseases/en/ cvd_atlas_25_future.pdf.

[2] Hong Kong Centre for Health Protection, Death Rates for Leading Causes of Death, 2001-2009, 2010, http://www.chp.gov.hk/ en/data/4/10/27/117.html.

[3] M. C. Craig-Schmidt, "World-wide consumption of trans fatty acids," Atherosclerosis Supplements, vol. 7, no. 2, pp. 1-4, 2006.

[4] European Food Safety Authority, "Opinion of the scientific panel on dietetic products, nutrition and allergies [NDA] related to the presence of trans fatty acids in foods and the effect on human health of the consumption of trans fatty acids," 2007, http://www.efsa.europa.eu/EFSA/efsa_locale-1178620753812_ 1178620767491.htm.

[5] World Health Organization, "Population nutrient intake goals for preventing diet-related chronic diseases," in Joint WHO/FAO Expert Consultation on Diet, Nutrition and the 
Prevention of Chronic Diseases, WHO Technical Report Series 916, chapter 5, 2003, http://whqlibdoc.who.int/trs/WHO_TRS_ 916.pdf.

[6] Dietary Guidelines Advisory Committee, Fats in the Report of the Dietary Guidelines Advisory Committee on Dietary Guidelines for Americans, Part D: Science Base, Section 4, 2005,http:// www.health.gov/dietaryguidelines/dga2005/report/HTML/ D4_Fats.htm.

[7] Health Canada, "TRANSforming the food supply is the final report of the trans fat task force," Health Canada and the Heart and Stroke Foundation of Canada, submitted to the Minister of Health, 2013, http://www.hc-sc.gc.ca/fn-an/nutrition/ gras-trans-fats/tf-ge/tf-gt_rep-rap-eng.php.

[8] Senate and House of Representatives of the Republic of the Philippines in Congress, "House Bill no. 330: Trans fat labeling requirements on food product labels and banning harmful trans fat in food," http://www.congress.gov.ph/download/basic_15/ HB00330.pdf.

[9] New York City Department of Health and Mental Hygiene, The Regulation to Phase Out Artificial Trans Fat in New York City Food Service Establishments, 2008, http://www.nyc.gov/ $\mathrm{html} / \mathrm{doh} /$ downloads/pdf/cardio/cardio-transfat-bro.pdf.

[10] Danish Nutrition Council, The Influence of Trans Fatty Acids on Health, 4th edition, 2003, http://www.meraadet.dk/gfx/uploads/rapporter_pdf/Trans\%20fatty\%20acids_4.th\%20ed._UK_ www.pdf.

[11] US Food and Drug Administration, "Federal register-68 FR 41433 July 11, 2003: food labeling; trans fatty acids in nutrition labeling; consumer research to consider nutrient content and health claims and possible footnote or disclosure statements; final rule and proposed rule," 2005, https://www.federalregister .gov/regulations/0910-AC50/food-labeling-trans-fatty-acidsin-nutrition-labeling-consumer-research-to-consider-nutrient-content.

[12] Health Canada, “Trans fat," 2009, http://www.hc-sc.gc.ca/fnan/nutrition/gras-trans-fats/index-eng.php.

[13] T. Leth, H. G. Jensen, A. A. Mikkelsen, and A. Bysted, "The effect of the regulation on trans fatty acid content in Danish food," Atherosclerosis Supplements, vol. 7, no. 2, pp. 53-56, 2006.

[14] M. J. Albers, L. J. Harnack, L. M. Steffen, and D. R. Jacobs Jr., "2006 marketplace survey of trans-fatty acid content of margarines and butters, cookies and snack cakes, and savory snacks," Journal of the American Dietetic Association, vol. 108, no. 2, pp. 367-370, 2008.

[15] W. M. N. Ratnayake, M. R. L’Abbe, and D. Mozaffarian, "Nationwide product reformulations to reduce trans fatty acids in Canada: when trans fat goes out, what goes in?" European Journal of Clinical Nutrition, vol. 63, no. 6, pp. 808-811, 2009.

[16] S. M. Downs, A. M. Thow, and S. R. Leeder, "The effectiveness of policies for reducing dietary trans fat: a systematic review of the evidence," Bulletin of the World Health Organization, vol. 91, pp. 262H-269H, 2013.

[17] S. M. Teegala, W. C. Willett, and D. Mozaffarian, "Consumption and health effects of trans fatty acids: a review," Journal of AOAC International, vol. 92, no. 5, pp. 1250-1257, 2009.

[18] D. Ansorena, A. Echarte, R. Ollé, and I. Astiasarán, “2012: No trans fatty acids in Spanish bakery products," Food Chemistry, vol. 138, no. 1, pp. 422-429, 2013.

[19] M. Roe and P. M. Finglas, "UK food composition dataupdating the McCance and Widdowson integrated dataset," Journal of the Association of Public Analysts, vol. 40, pp. 69-70, 2012, http://www.apajournal.org.uk/2012_0069-0070.pdf.
[20] Hong Kong Department of Justice, Cap 132W Food and Drugs (Composition and Labelling) Regulations, 2010, http://www .legislation.gov.hk/blis_ind.nsf/WebView?OpenAgent\&vwpg= CURALLENGDOC $* 132 * 100 * 132.24 \# 132.24$.

[21] AOAC, Official Methods of Analysis of AOAC International (OMA), 19th edition, 2012.

[22] Hong Kong Centre for Food Safety, Technical Guidance Notes on Nutrition Labelling and Nutrition Claims, 2008, http://www.cfs .gov.hk/english/food_leg/files/nl_technical_guidance_e.pdf.

[23] J. McCarthy, D. Barr, and A. Sinclair, "Determination of trans fatty acid levels by FTIR in processed foods in Australia," Asia Pacific Journal of Clinical Nutrition, vol. 17, no. 3, pp. 391-396, 2008.

[24] M. M. Mossoba, J. Moss, and J. K. G. Kramer, “Trans fat labeling and levels in U.S. foods: assessment of gas chromatographic and infrared spectroscopic techniques for regulatory compliance," Journal of AOAC International, vol. 92, no. 5, pp. 1284-1300, 2009.

[25] M. A. van Erp-Baart, C. Couet, C. Cuadrado, A. Kafatos, J. Stanley, and G. van Poppel, "Transfatty acids in bakery products from 14 european countries: the TRANSFAIR study," Journal of Food Composition and Analysis, vol. 11, no. 2, pp. 161-169, 1998.

[26] W. M. N. Ratnayake, M. R. Labbé, S. Farnworth et al., “Trans fatty acids: current contents in Canadian foods and estimated intake levels for the Canadian population," Journal of AOAC International, vol. 92, no. 5, pp. 1258-1276, 2009.

[27] P. M. Fernández and S. Juan, "Fatty acid composition of commercial Spanish fast food and snack food," Journal of Food Composition and Analysis, vol. 13, no. 3, pp. 275-281, 2000.

[28] E. K. Richter, K. A. Shawish, M. R. L. Scheeder, and P. C. Colombani, "Trans fatty acid content of selected Swiss foods: the TransSwissPilot study," Journal of Food Composition and Analysis, vol. 22, no. 5, pp. 479-484, 2009.

[29] H. Fu, L. Yang, H. Yuan, P. Rao, and Y. M. Lo, "Assessment of trans fatty acids content in popular Western-style products in China," Journal of Food Science, vol. 73, no. 8, pp. S383-S391, 2008.

[30] A. Baylin, X. Siles, A. Donovan-Palmer, X. Fernandez, and H. Campos, "Fatty acid composition of Costa Rican foods including trans fatty acid content," Journal of Food Composition and Analysis, vol. 20, no. 3-4, pp. 182-192, 2007.

[31] A. Aro, E. Amaral, H. Kesteloot, A. Rimestad, M. Thamm, and G. van Poppel, "Transfatty acids in French fries, soups, and snacks from 14 european countries: the TRANSFAIR study," Journal of Food Composition and Analysis, vol. 11, no. 2, pp. 170177, 1998. 

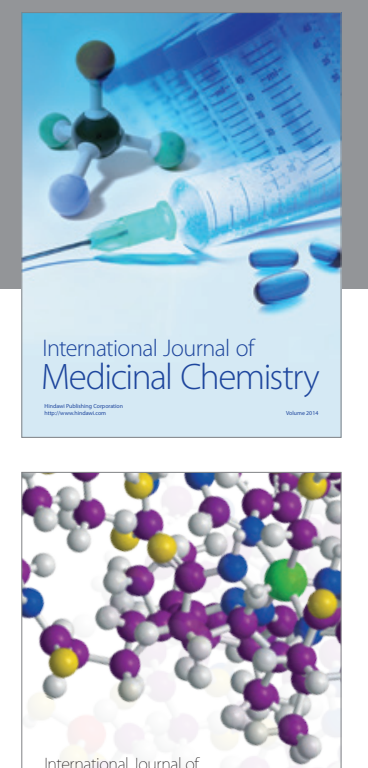

\section{Carbohydrate} Chemistry

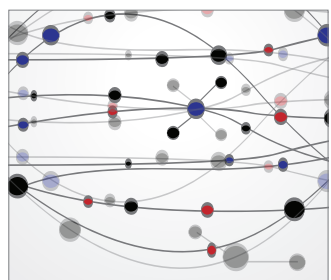

The Scientific World Journal
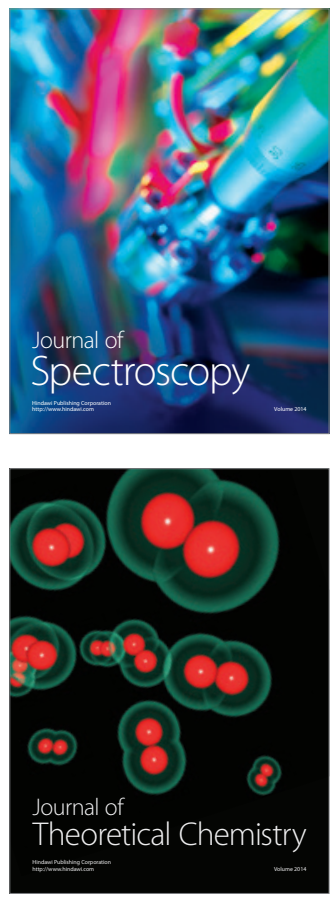
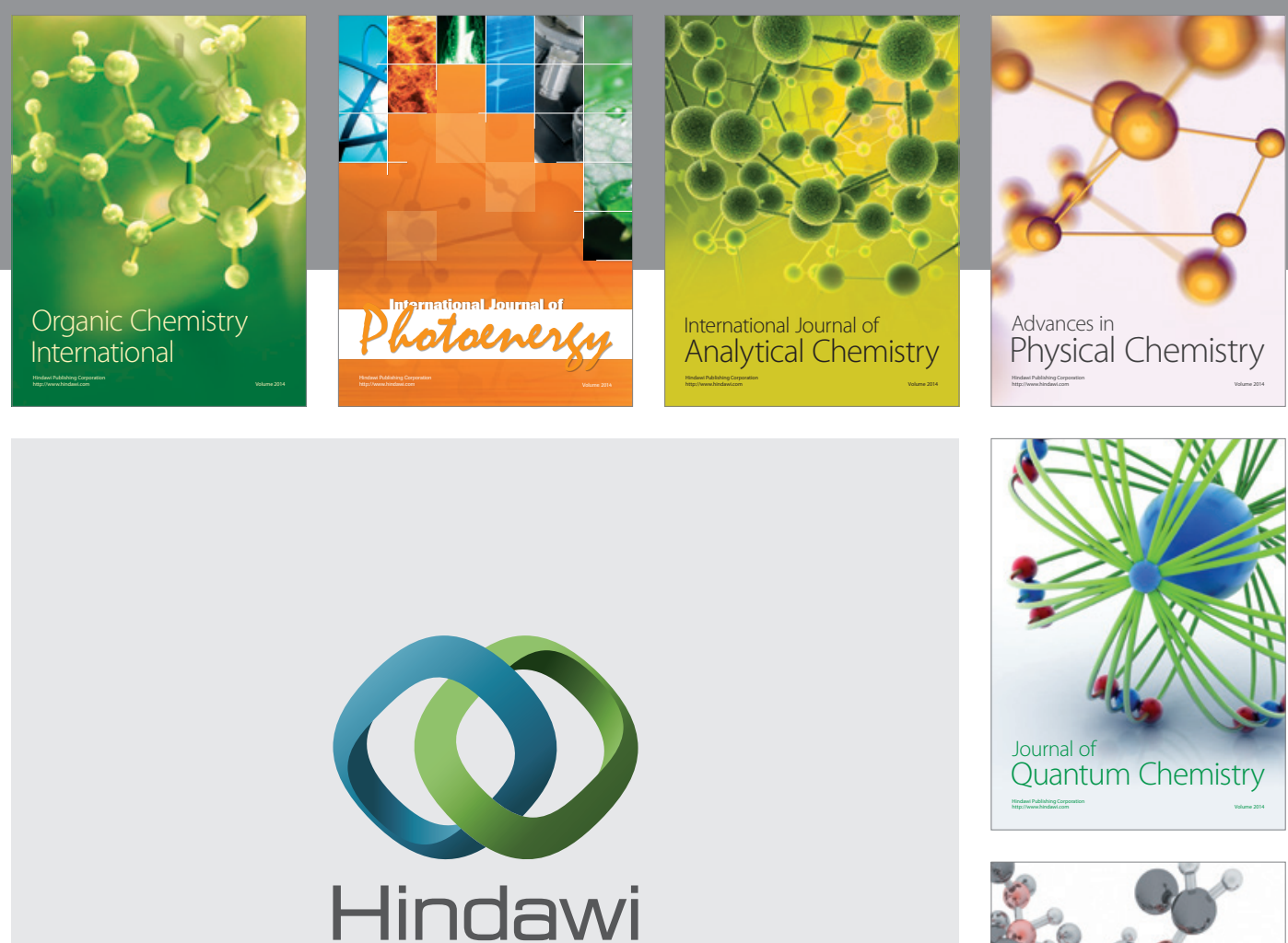

Submit your manuscripts at

http://www.hindawi.com

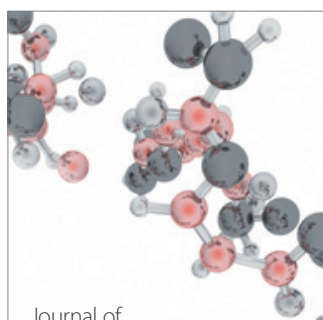

Analytical Methods

in Chemistry

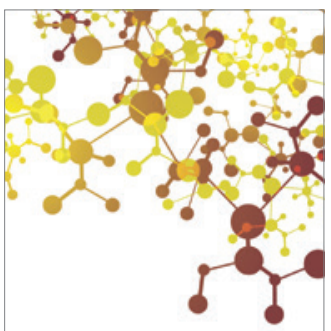

Journal of

Applied Chemistry

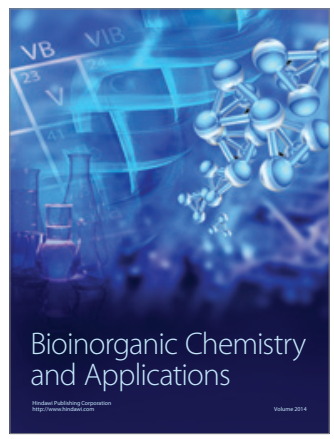

Inorganic Chemistry
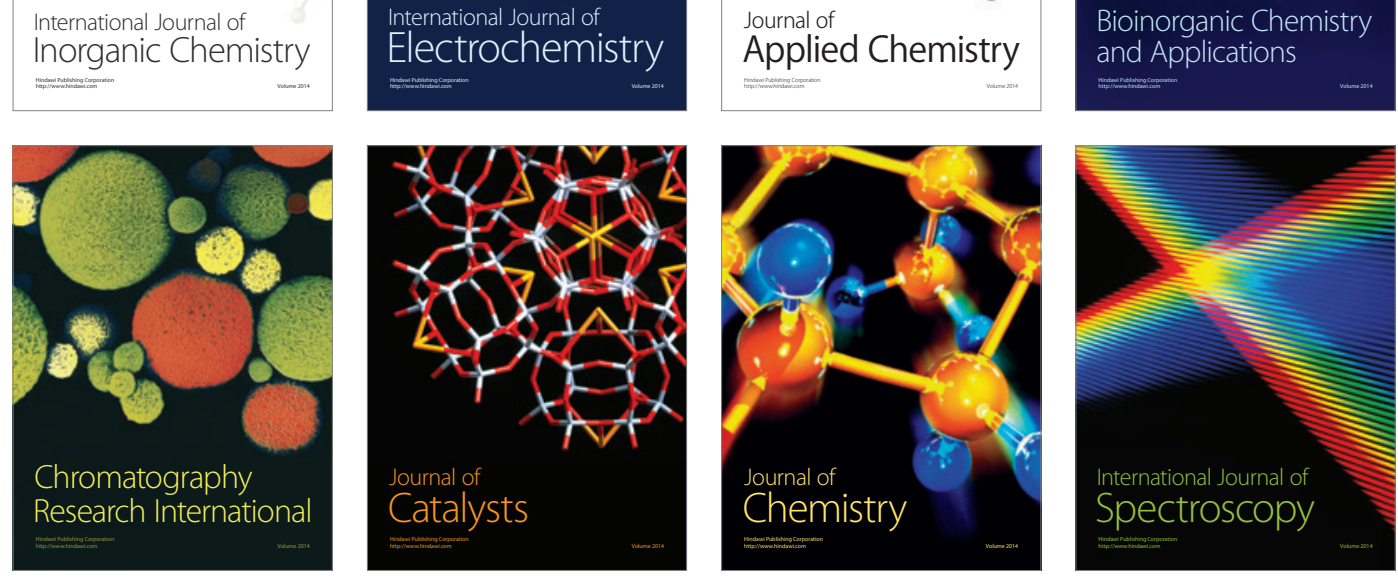